\title{
Correction to: Better Scared than Sorry: The Pragmatic Account of Emotional Representation
}

\author{
Kris Goffin ${ }^{1,2}$ (ID
}

๑ Springer Nature B.V. 2021

\section{Correction to: Erkenntnis https://doi.org/10.1007/s10670-021-00470-1}

In the original publication of this article, the grant number $1217120 \mathrm{~N}$ was missed mistakenly in the Funding section. Below is the updated funding section of the article.

The original article has been corrected.

Funding Kris Goffin is the holder of a Research Foundation - Flanders (FWO) Junior Postdoctoral Fellowship (1217120N). This paper is based on Kris Goffin's doctoral research at Ghent University and the University of Antwerp, funded by Ghent University.

Publisher's Note Springer Nature remains neutral with regard to jurisdictional claims in published maps and institutional affiliations.

The original article can be found online at https://doi.org/10.1007/s10670-021-00470-1.

Kris Goffin

kris.goffin@uantwerpen.be

1 Centre for Philosophical Psychology - Department of Philosophy, Faculty of Arts and Philosophy, University of Antwerp, Lange Sint-Annastraat 7 - S.208, 2000 Antwerp, Belgium

2 Faculty of Psychology and Educational Sciences, Research Group of Quantitative Psychology and Individual Differences, KU Leuven, Leuven, Belgium 